\title{
EfFects of Body Position on The Ventilatory Response TO HYPERCAPNIA
}

\author{
Zh. A. Donina, G. A. Danilova, N. P. Aleksandrova \\ Pavlov Institute of Physiology, Russian Academy of Science, Saint-Petersburg, Russia
}

\begin{abstract}
Effect of posture on the hypercapnic ventilatory response was studied on the anaesthetized rats by using rebreathing techniques in the supine and head-down positions. There were no statistically significant alterations in tidal volume, frequency, minute ventilation, and $\mathrm{P}_{\mathrm{ET}} \mathrm{CO}_{2}$ between the head-down and supine positions during breathing at rest. However, the esophageal pressure inspiratory swings were significantly greater in the head-down compared with supine position. Moreover, we found that body position did not affect the hypercapnic ventilatory response, but did affect the relationship between inspiratory driving pressure and the increase of end tidal $\mathrm{PCO}_{2}$. Greater inspiratory pressure is required to maintain the same level of the ventilatory response to hypercapnia in the horizontal position with the head-down. We believe that the discrepancy between postural alterations in the hypercapnic ventilatory and pressure responses is presumably a result of decreased lung compliance and increased airflow impedance of respiratory system in the head-down position.
\end{abstract}

Key words: respiration, body position, central hypervolemia, hypercapnia, ventilatory responsiveness.

\section{INTRODUCTION}

Changes in the body position from upright to both supine and head-down evoke central hypervolemia induced by increased venous return because of volume shift from the peripheral to central compartment. It has been shown that central hypervolemia is induced during episodes of obstructive sleep apnea, asthmatic attack, and also when microgravity. Our previous study has found that in anesthetized animals central hypervolemia increases respiratory resistance, decreases lung ventilation, and weakens compensatory response to mechanical loading [1]. The aim of the present study was to investigate the influence of hypervolemia on the chemical control of breathing.

Postural influences on ventilatory responsiveness to chemoreceptor stimuli have already been shown. The ventilatory responses to hypoxia and hypercapnia were measured in normal subjects in the upright, sitting, and supine positions. Most studies have reported a substantial reduction in the hypoxic ventilatory response in the supine position compared with that in the upright position in humans [2, 3, 4, 5]. It has also been suggested that the ventilatory response to $\mathrm{CO}_{2}$ is not influenced by changes in posture. However, responses to peripheral and central chemoreceptor stimuli seem identical and essentially independent of body position [6]. No statistically significant differences in the ventilatory response, tidal volume response, and frequency response to hypoxia between the lying and sitting postures have been found [7]. On the other hand, in normal subjects during hypercapnic stimulated breathing, ventilation was less in the supine than seated position [8]. Yoshisaki et al [9] reported a shift in the $\mathrm{CO}_{2}$ ventilatory response curve upward or leftward in the head-up compared with supine position.

The purpose of present study was to investigate the effects of the head-down position on the ventilatory and inspiratory driving pressure responses to hyperoxic progressive hypercapnia in experimental animals.

\section{Material AND Methods}

The study was approved by a local Ethics Committee. The experiments were performed on 18 tracheotomized rats (mean weight $300 \pm 10 \mathrm{~g}$ ), which were anesthetized with urethane $(1 \mathrm{~g} / \mathrm{kg}$, i.p.). The level of anesthesia was sufficient to eliminate pain reflexes. Assessing corneal reflex and responses to tactile stimuli monitored the anesthetic depth. Tracheostomy was performed through a midline ventral neck incision. Cannula inserted into distal part of trachea bellow the larynx.

The hypercapnic ventilatory response was measured by using rebreathing techniques. The hyperoxic, progressive hypercapnia rebreathing was carrying out by a modified form of the Read rebreathing method [10]. For the hypercapnic rebreathing test, animals breathed from a bag with gas mixture of $60 \% \mathrm{O}_{2}, 7 \% \mathrm{CO}_{2}$, balanced with $\mathrm{N}_{2}$. The end-tidal fraction of $\mathrm{CO}_{2}$ $\left(\mathrm{P}_{\mathrm{ET}} \mathrm{CO}_{2}\right)$ was analyzed by a rapidly responding quadruple mass spectrometer (model MC-100, Institute of analytic instrument-making, RAS), which was calibrated immediately before and after use with known gas mixtures carried onboard. A gradual rise in the end-tidal $\mathrm{CO}_{2}$ concentration was recorded for 4 min and was monitored on a breath-to-breath basis. At the end of rebreathing period, end-tidal $\mathrm{O}_{2}$ was on average more than $190 \mathrm{mmHg}$, eliminating the possibility of any hypoxic stimulus. The hypercapnic ventilatory responses were performed in the supine and headdown positions (the tilt on -30 degree rotation). The 
baseline record was taken in supine position when the control parameters stabilized. After that animals were shifted in head-down tilt (HDT) position for $30 \mathrm{~min}$.

Pneumotachography was used to measure peak airflow and respiratory rate. Airflow integrated to volume. The value for minute ventilation was calculated from the mean tidal volume and respiratory frequency of ten respiratory cycles.

Records of the esophageal pressure inspiratory swings $\left(\mathrm{P}_{\text {esI }}\right)$ were used as indirect measure of the force of inspiratory muscle contractions and as a reflection of inspiratory driving pressure. Latex balloon positioned in the lower one-third of the esophagus allowed measuring esophageal pressure swings. The balloon was filled with air and connected via catheters (inner diameter $1.5 \mathrm{~mm}$, length $30 \mathrm{~cm}$ ) to a differential pressure transducer.

Both responses of tidal volume $\left(V_{T}\right)$, frequency $(f)$, minute ventilation $\left(\mathrm{V}_{\mathrm{E}}\right)$ and esophageal pressure $\left(\mathrm{P}_{\mathrm{esI}}\right)$ to increase in $\mathrm{P}_{\mathrm{ET}} \mathrm{CO}_{2}$ were analyzed by linear regression. The slope of ventilatory response to hypercapnia as $\Delta \mathrm{V}_{\mathrm{E}} / \Delta \mathrm{P}_{\mathrm{ET}} \mathrm{CO}_{2}$ and the slope of esophageal pressure response to hypercapnia as $\Delta \mathrm{P}_{\text {esI }} / \Delta \mathrm{P}_{\mathrm{ET}} C \mathrm{O}_{2}$ were obtained at $\mathrm{P}_{\mathrm{ET}} \mathrm{CO}_{2}$ of $65 \mathrm{mmHg}$ in both supine and head-down tilt positions.
Data were expressed as means \pm SE. Statistical comparisons between measurements in supine position and at $30 \mathrm{~min}$ in head-down position were performed using one-way analysis of variance for repeated measures. Differences were considered significant at a value of $\mathrm{P}<0.05$.

\section{RESULTS}

Table 1 demonstrates indices of breathing pattern in anaesthetized tracheostomized animals in supine and HDT position during rest breathing. There were no statistically significant alterations in tidal volume, frequency, minute ventilation, and $\mathrm{P}_{\mathrm{ET}} \mathrm{CO}_{2}$ in HDT position compared with the supine position. At the same time, the esophageal pressure inspiratory swings were significantly greater in the head-down position.

When hypercapnia stimulated breathing, a significant correlation between $\mathrm{V}_{\mathrm{E}}, \mathrm{V}_{\mathrm{T}}$ and increase in $\mathrm{P}_{\mathrm{ET}} \mathrm{CO}_{2}$ was found in both supine and HTD positions (Fig. 1 Panels A and B). Respiratory rate did not correlate with the gradual rise in the end-tidal $\mathrm{CO}_{2}$ concentration in both positions (Fig. 1, Panel C). A comparison of the $V_{E}$ and $V_{T}$ responses to hypercapnia revealed no significant differences between the two body
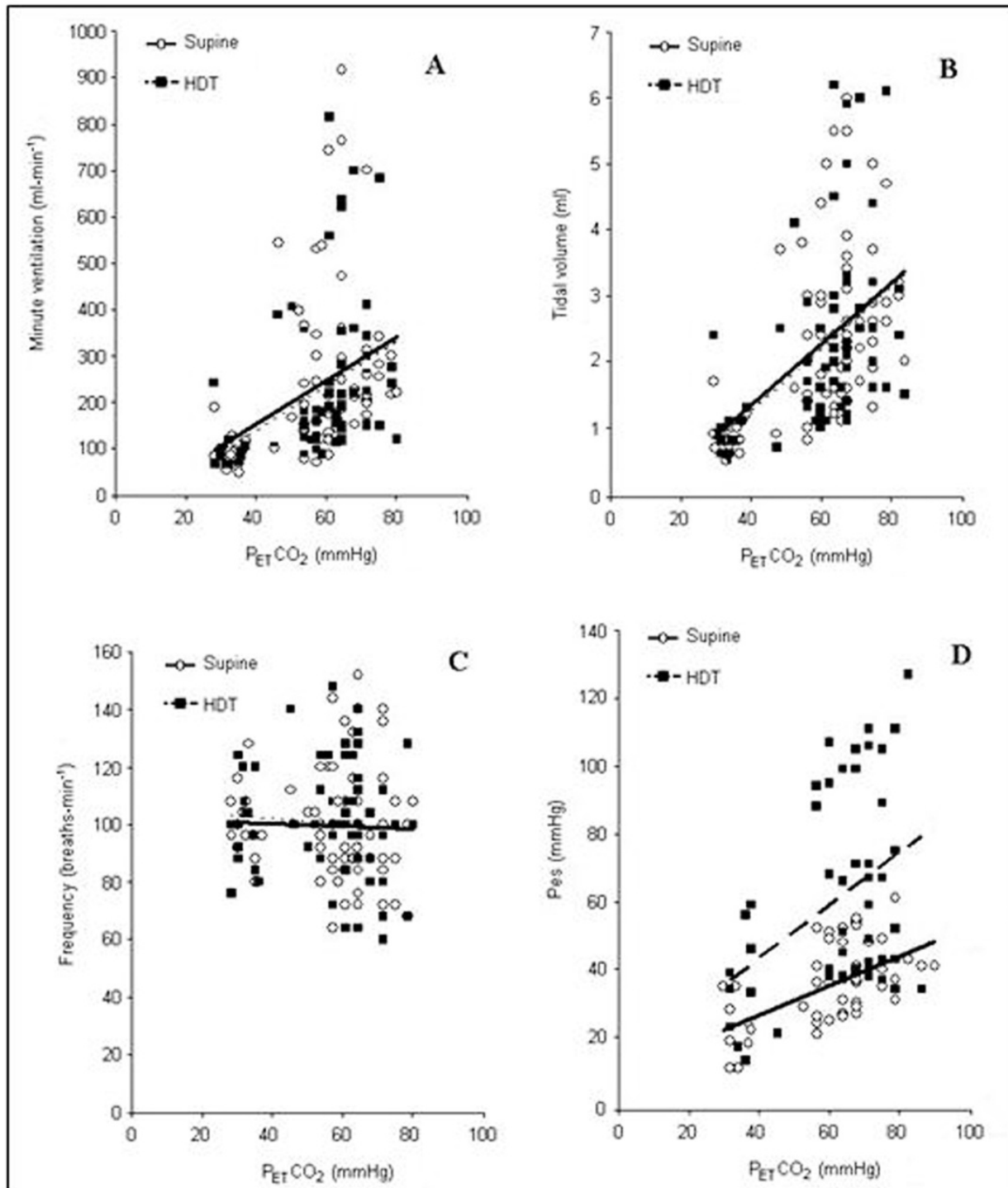

Fig. 1. Regression curves describing the relationship between minute ventilation (A), tidal volume $(\mathrm{B})$, respiratory frequency $(C)$, and esophageal pressure (D), on one side, and progressive hypercapnia in the supine (solid lines) and headdown-tilt (dashed lines) positions, on the other side. 


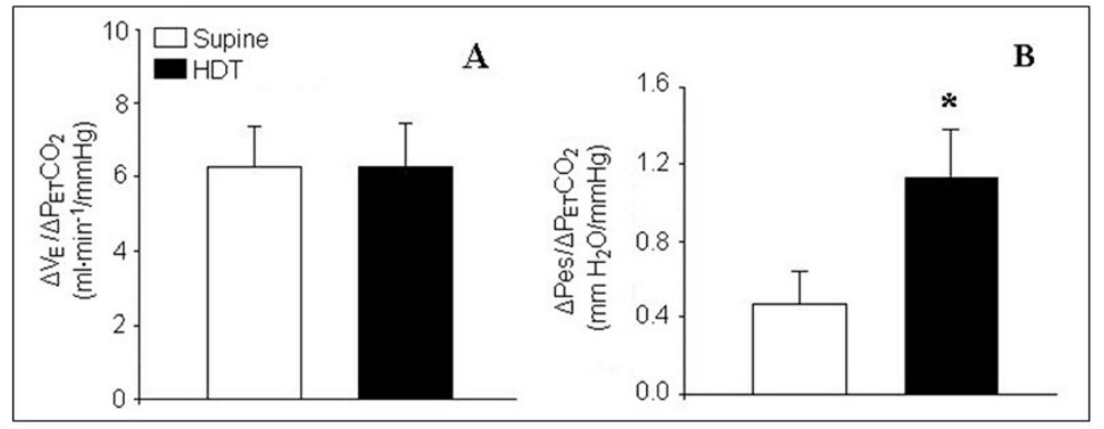

Fig. 2. Slope of the ventilatory (A) and esophageal pressure (B) responses to hypercapnia at $\mathrm{P}_{\mathrm{ET}} \mathrm{CO}_{2}$ of $65 \mathrm{mmHg}$ in both supine and head-down tilt positions. ${ }^{*}$ S Significant difference between the slopes in supine and head down-tilt (HDT) positions $(\mathrm{P}<0.05)$.
Table 1. Indices of breathing pattern in anesthetized tracheostomized rats in supine and HDT positions during breathing at rest.

\begin{tabular}{ccc}
\hline Indices & Supine & HDT \\
\hline $\mathrm{P}_{\mathrm{ET}} \mathrm{CO}_{2}(\mathrm{mmHg})$ & $32.8 \pm 3.1$ & $33.0 \pm 2.8$ \\
$\mathrm{~V}_{\mathrm{T}}(\mathrm{ml})$ & $0.9 \pm 0.1$ & $0.9 \pm 0.1$ \\
$\mathrm{f}\left(\mathrm{min}^{-1}\right)$ & $100 \pm 10$ & $108 \pm 19$ \\
$\mathrm{~V}_{\mathrm{E}}\left(\mathrm{ml} \cdot \mathrm{min}^{-1}\right)$ & $91.1 \pm 8.4$ & $93.1 \pm 10.8$ \\
$\mathrm{P}_{\mathrm{esI}}\left(\mathrm{mmH}_{2} \mathrm{O}\right)$ & $22.5 \pm 2.9$ & $34.6 \pm 5.2^{*}$ \\
\hline
\end{tabular}

$\mathrm{P}_{\mathrm{ET}} \mathrm{CO}_{2}$ - end-tidal fraction of $\mathrm{CO}_{2} ; \mathrm{V}_{\mathrm{T}}$ - tidal volume; $\mathrm{f}$ inspiratory rate; $\mathrm{V}_{\mathrm{E}}$ - minute ventilation; $\mathrm{P}_{\mathrm{esI}}$ - peak esophageal pressure; Values are means \pm SE. $*$ Significant difference from the supine position; $\mathrm{P}<0.05$.

positions. As shown in Fig. $1, \mathrm{~V}_{\mathrm{E}}-\mathrm{P}_{\mathrm{ET}} \mathrm{CO}_{2}$ and $\mathrm{V}_{\mathrm{T}}$ $\mathrm{P}_{\mathrm{ET}} \mathrm{CO}_{2}$ relationships were practically identical in the supine and HDT positions. The slope of the ventilatory response to hypercapnia, which reflects the rate at which ventilation rises with increasing $\mathrm{P}_{\mathrm{ET}} \mathrm{CO}_{2}$, was the same in both position and amounted to $6.3 \pm 1.4$ and $6.3 \pm 1.3 \mathrm{ml} \cdot \mathrm{min}^{-1} \cdot \mathrm{mmHg}^{-1}$, respectively (Fig. 2, Panel A). However, our data demonstrated significant differences in the inspiratory pressure response related to alterations in the body position. The increase in PesI seen during hypercapnia in the supine position was significantly less than that in the HDT position.

Fig.1 (Panel D) illustrates that the relationship between $\mathrm{P}_{\text {esI }}$ and $\mathrm{P}_{\mathrm{ET}} \mathrm{CO}_{2}$ was steeper when head-down than supine. The slope of the pressure response to hypercapnia amounted to $0.47 \pm 0.04 \mathrm{mmH}_{2} \mathrm{O} \cdot \mathrm{mm} \mathrm{Hg}^{-1}$ in the supine position and $1.14 \pm 0.18 \mathrm{mmH}_{2} \mathrm{O} \cdot \mathrm{mmHg}^{-1}$ in the HDT position. Thus the rate at which inspiratory pressure rose with increasing $\mathrm{P}_{\mathrm{ET}} \mathrm{CO}_{2}$, was 2.4-fold greater in the HDT than supine position $(\mathrm{P}<0.01)$ (Fig. 2, Panel B).

\section{DISCUSSION}

We observed, as did other investigators [11, 12], that ventilatory responses to hypercapnia were not related to alterations in the body position. Ventilatory responsiveness to $\mathrm{CO}_{2}$ was the same in the two body position (supine and head-down tilt). Our previous study has shown that in contrast to the hypercapnic ventilatory response, the hypoxic ventilatory response decreases in the head-down position [5]. These data are in accord with the results of studies in which hypoxic ven- tilatory responses were compared in the standing or sitting postures compared with the supine position [4, 9]. Thus, change in the body position affects differentially hypoxic and hypercapnic sensitivity of the breathing system, decreasing the ventilatory response to hypoxia, but not to hypercapnia. The reduction in the hypoxic response in the HDT position compared with that in the supine position may be related to changes in the activity of arterial chemoreceptors. As it known, carotid body chemoreceptors respond markedly to changes in blood pressure when conditions are hypoxic, becoming less active as blood pressure increases [3]. In the HDT position, there is a substantial increase in blood pressure at the level of the carotid bodies. In contrast to the hypoxic ventilatory response, the hypercapnic response is determined by the activation of central chemoreceptors whose activity is not directly related to alteration in blood pressure.

Moreover, our data demonstrated that although the hypercapnic ventilatory response was not altered by a change in body position, the pressure response to hypercapnia was significantly increased in the HDT compared with the supine position. Thus, greater inspiratory driving pressure was required to maintain the same level of the ventilatory response to hypercapnia compared with the horizontal position with headdown. The increase in the negative intrathoracic pressure observed in the present study points to the intensification of inspiratory muscle efforts in the HDT position during the hypercapnic stimulated breathing. This speculation is confirmed by results of another study which have shown that different body positions are accompanied by alterations in the activity of respiratory muscles [11]. Moreover, while the slopes of the ventilatory response to increasing arterial $\mathrm{CO}_{2}$ tension were similar in the supine and sitting positions, the EMG- $V_{E}$ relationship showed steeper slopes in the supine than sitting position. Despite similar ventilatory responses to $\mathrm{CO}_{2}$-rebreathing in the lying and upright positions, the supine position in humans required a higher activation of inspiratory muscles [11].

We believe that the discrepancy between postural alterations in the hypercapnic ventilatory and pressure responses is presumably a result of decreased lung compliance and increased airflow impedance of the respiratory system in the HDT position. Our previous study has shown that central hypervolemia evoked by tilting significantly increases mechanical loading [1]. Significant increases in both resistive and elastic component of respiratory resistance were found in the HDT compared with supine position. An increase in the central venous pressure can cause a swelling of the 
bronchial mucosa $[13,14]$. Beside, a larger intrathoracic blood volume evokes an increase in lung elastic recoil [15]. In their turn, airway dimensions and resistance are dependent on lung recoil pressure. As it is known, increased mechanical loading limits ventilatory responses of the respiratory system to chemoreceptor stimulation. So, a grater increase in inspiratory driving pressure in response to progressive hypercapnia in the HDT position was not evoked by the corresponding increase in the ventilatory response. At the same time, in contrast to the hypoxic ventilatory response, the hypercapnic response was not decreased in the HDT position. Similar results have been obtained in a study on the effects of posture on ventilatory responses in humans, where, with a shift from upright to supine position, the ventilatory response to hypoxia but not to hypercapnia was decreased [4].

Postural independence of the hypercapnic ventilatory response has an important biological significance, as a major function of the respiratory system is the elimination of surplus $\mathrm{CO}_{2}$ and the maintenance of $\mathrm{pH}$ and $\mathrm{PCO}_{2}$ within narrow limits despite an alteration evoked by metabolism or environment.

We conclude that central hypervolemia evoked by postural influence decreases ventilatory responsiveness to hypoxia and demands higher activation of the inspiratory muscles to maintain the postural independence of the ventilatory response to hypercapnia. These alterations in the chemoreceptor control of breathing further weaken the compensatory opportunities of the respiratory system during the head-down body position.

Acknowledgments: Supported by the Russian Foundation for Basic Research (RFBR) grants No. 06-04-48126 and 09-0401662 .

Conflicts of interest: The authors declared no conflict of interest in relation to this article.

\section{REFERENCES}

[1] Aleksandrova N P, Donina Zh A, Danilova G A. Effect of central hypervolemia on respiratory function. J Physiol Pharmacol 2007; 58 Suppl 5: 9-15.

[2] Xie A, Takasaki Y, Popkin J, Orr D, Bradley T.D. Chemical and postural influence on scalene and diaphragmatic activation in humans. J Appl Physiol 1991; 70: 658-664.
[3] Somers V K, Mark A L, Abboud F M. Interaction of baroreceptor and chemoreceptor reflex control of sympathetic nerve activity in normal humans. J Clin Invest 1991; 87: 1953-1957.

[4] Xie A, Takasaki Y, Popkin J, Orr D, Bradley T.D. Influence of body position on pressure and airflow generation during hypoxia and hypercapnia in man. J Physiol 1993; 465: 477-487.

[5] Aleksandrova N P, Donina Zh A, Danilova G A, Tikhonov M A, Baranov V M. The ventilatory response to isocapnic hypoxia during head-down tilt. Russian J Physiol 2008; 94: 1414-1419.

[6] Mannix S E, Bye P, Hughes J M, Cover D, Davies E. Effect of posture on ventilatory response to steady-state hypoxia and hypercapnia. Respir Physiol 1984; 58: 87-99.

[7] Slutsky A S, Goldstein R G, Rebuck A S. The effect of posture on the ventialtory response to hypoxia. Can Anaesth Soc J 1980; 27: 445-448.

[8] Weissman C, Abraham B, Askanazi J, Milic-Emili J, Hyman A I, Kinney J M. Effect of posture on the ventilatory response to $\mathrm{CO}_{2}$. J Appl Physiol 1982; 53: 761-765.

[9] Yoshisaki H, Yoshida A, Hayashi F, Fukuda Y. Effect of posture change on control of ventilation. Jpn J Physiol 1998; 48: 267-273.

[10] Read D J. A clinical method for assessing the ventilatory response to carbon dioxide. Australas Ann Med 1967; 16: 20-32.

[11] Wanke T, Lahrmann H, Formanek D, Zwick H. Effect of posture on inspiratory muscle electromyogram response to hypercapnia. Eur J Appl Physiol Occup Physiol 1992; 64: 266-271.

[12] Prisk G K. Microgravity and lung. J Appl Physiol 2000; 89: 385-396. Review.

[13] Mead J. Analysis of the configuration of maximum expiratory flow-volume carves. J Appl Physiol 1978; 44: 156165.

[14] Navajas D, Farre R, Rotger M, Milic-Emili J, Sanchis J. Effect of body posture on respiratory impedance. J Appl Physiol 1988; 64: 194-199.

[15] Prefaut C, Lupih E, Anthonisen N. Human lung mechanics during water immersion. J Appl Physiol 1976; 40: 320323.

Corresponding author:

Nina Aleksandrova

nab. Makarova 6 St.

St. Petersburg, 199034, Russia

Phone/Fax: + 7(813) 7072757

E-mail: n_aleks@yahoo.com

breath@kolt.infran.ru 